Kruijver, I.P.M., Kerkstra, A., Bensing, J.M., Wiel, H.B.M. van der

Communication skills of nurses during interactions with simulated cancer patients.

Journal of Advanced Nursing: 34, 2001, nr. 6, p. 772-779

\begin{tabular}{l|l} 
Postprint Version & 1.0 \\
Journal website & $\underline{\text { http://www.blackwell-synergy.com }}$ \\
\hline Pubmed link & $\begin{array}{l}\text { http://www.ncbi.nlm.nih.gov/entrez/query.fcgi?cmd=Retrieve\&db=pubmed\&dop } \\
\text { t=Abstract\&list uids=11422547\&query hl=28\&itool=pubmed docsum }\end{array}$ \\
\hline DOI &
\end{tabular}

Correspondence: Irma Kruijver, Netherlands Institute of Primary Health Care (NIVEL), PO Box 1568, 3500 BN Utrecht, The Netherlands. E-mail: i.kruyver@nivel.nl

\title{
Communication skills of nurses during interactions with simulated cancer patients
}

IRMA P.M. KRUIJVER MSC - Research Fellow, Netherlands Institute for Health Services Research, Utrecht, The Netherlands

ADA KERKSTRA PHD - Co-ordinator, Department of Nursing and Caring Research, Netherlands Institute for Health Services Research, Utrecht, The Netherlands

JozIEN M. BENSING PHD - Director, Netherlands Institute for Health Services Research, Utrecht, and Department of Clinical and Health Psychology, University of Utrecht, Utrecht, The Netherlands

AND HARRY B.M. VAN DE WIEL PHD - University of Groningen, Department of Medical Psychology, Groningen, The Netherlands

Aim. In this paper the balance of affective and instrumental communication employed by nurses during the admission interview with recently diagnosed cancer patients was investigated.

Rationale. The balance of affective and instrumental communication employed by nurses appears to be important, especially during the admission interview with cancer patients.

Methods. For this purpose, admission interviews between 53 ward nurses and simulated cancer patients were videotaped and analysed using the Roter Interaction Analysis system, in which a distinction is made between instrumental and affective communication.

Results. The results reveal that more than $60 \%$ of nurses' utterances were of an instrumental nature. Affective communication occurred, but was more related to global affect ratings like giving agreements and paraphrases than to discussing and exploring actively patients feelings by showing empathy, showing concern and optimism.

Conclusion. In future, nurses should be systematically provided with (continuing) training programmes, in which they learn how to communicate effectively in relation to patients' emotions and feelings, and how to integrate emotional care with practical and medical tasks.

\section{INTRODUCTION}

It is widely known that in cancer nursing, communication with patients is emotionally laden (Northouse \& Northouse 1987, Maguire \& Faulkner 1988, Chaitchik et al. 1992, Faulkner 1993). Cancer is a life-threatening disease and medical treatment can have far-reaching consequences. Consequently, many cancer patients seem to experience distress after diagnosis (Fallowfield 1988, Maguire \& Faulkner 1988, Harrison et al. 1994, Maguire 1995). When these patients have to be 
admitted to hospital for treatment, ward nurses, in particular, are closely involved with patients' concerns as they provide 24 hour care. Accordingly, communication is one of the most important aspects of nursing care in an oncology setting (Wilkinson 1991). In line with research into doctorpatient communication, two types of communicative behaviours employed by nurses seem to be important in meeting the cognitive and especially the affective needs of cancer patients. In the first place, these include instrumental behaviours, which are of significance in informing the patient about the illness and treatment, and providing medical and practical care. In the second place, they include affective behaviours, such as showing respect, giving comfort and trust which are important in building a relationship with the patient, in which s/he has a sense of being understood (Hall et al. 1987, Bensing 1991), and in creating a trustful atmosphere, in which the patient is helped to disclose information and concerns relating to their confrontation with a life threatening disease (Wouda \& Van de Wiel 1996).

However, the emotional load in cancer nursing makes interactions between nurses and patients difficult. Research shows that nurses' communication exhibits more negative or blocking features than positive facilitative ones during interactions with cancer patients (Kruijver et al. 2000a). These blocking behaviours are characterized by overwhelming patients with medical information (Dennison 1995), failing to establish what patients understand about their illness and treatment (Dennison 1995), an overwhelming concern with the physical care and treatment problems (Bond 1983), use of closed questions (Maguire et al. 1996), not being able to assess problems and concerns, and not being able to get patients to disclose feelings (Webster 1981, Degner et al. 1991, Heaven \& Maguire 1996). These findings seem to disclose an imbalance in nurses' performance of both types of communication behaviours: nurses' affective communication is virtually entirely absent. Research shows that imbalance leads to dissatisfaction from cancer patients (Suominen et al. 1995). They view nurses' communication as unsupportive when the nurses pay no attention to the emotional component (Krishnasamy 1996a).

This paper focuses on the balance as regards affective and instrumental communication employed by nurses in a clinical oncology setting. The balance is particularly important during admission interviews with recently diagnosed cancer patients. At this time, the patient becomes acquainted with the nurse who, in the primary nursing system, will be primarily responsible for the care of the patient during his/her stay in hospital (Ersscher \& Tutton 1991). The admission interview usually starts with history taking, in which the nurse gathers information from the patient about medical and lifestyle issues relevant to treatment. The use of exploratory skills encouraging the patient to respond freely about affective and medical topics, alternating with skills that structure the conversation, are in consequence important (Wouda \& van de Wiel 1996). Another important nursing aspect of the admission interview concerns providing clear information about medical issues with regard to treatment, and providing clear information about ward organizational issues, and services during admission (Wouda \& van de Wiel 1996).

From the patient's perspective, the admission situation can cause emotional distress as it follows recent diagnosis of a life threatening disease, and admission for cancer treatment. In this situation, it is important for the nurse to be able to create an environment of trust, in which the patient feels respected, involved and accepted. In a good environment, the patient is helped to disclose concerns, which may relieve him/her. Relief, in turn may lead to an increased concentration, from patient's side, on the nurse's information and questions asked during admission. In such circumstances, a nurse's ability to adapt the information to the patient's emotional condition is of significance (Krishnasamy 1996b, Wouda \& van de Wiel 1996).

These nursing tasks during the admission interview show the significance in turn of affective and instrumental communication.

\section{THE STUDY}

\section{Background}

An exact picture as regards the ratio of instrumental to affective communication of nurses during interactions with cancer patients has never been investigated in nursing research before. Insight about this could give a more nuanced picture of the (im)balance between instrumental and affective communication employed by ward nurses in a clinical oncology setting. In relatively few studies the 
method of systematic observation with videotapes has been used (Kruijver et al. 2000a, b). This is preferred because it is the most direct and complete method of evaluating communication behaviours, including nonverbal communication. In most previous studies, communicative behaviours were measured with questionnaires and audiotapes. Consequently, nonverbal communication, which has been shown to be important during nurse-patient interactions, has hardly been investigated (Kruijver et al. 2000a, b).

\section{Aim}

This paper reports a direct observational study using video tapes. The study focuses on the balance of affective and instrumental communication employed by ward nurses during the admission interview with recently diagnosed cancer patients, including nonverbal communication.

The research question addressed was: what is the actual balance of affective and instrumental communication employed by ward nurses during the admission interview with recently diagnosed cancer patients?

\section{Methods}

\section{Sample}

In total, 53 registered (ward) nurses in different medical specialisms at three hospitals in the Netherlands participated in the study. All nurses had experience in caring for cancer patients. The three hospitals that participated were two university and one general. The nurses were recruited from 11 wards: gynaecology, urology, surgery, internal medicine/ haematology and ear, nose and throat diseases (ENT). In Table 1, background characteristics of the nurses are presented.

\section{[ TABLE 1 ]}

\section{Procedure}

Ethics committee approval for the study was provided by each of the three hospitals. The nurses were approached by the researcher (IK) and were informed about the purposes of the study both verbally (by means of holding presentations on the wards) and in writing. Potential participants were assured that anonymity of the results was guaranteed, and that they were free to withdraw. Then, enthusiastic nurses could sign up for participation.

This research is part of a randomized pretest-post-test study, in which the communication skills of these nurses during interactions with simulated patients, as well as with real cancer patients in daily practice, are investigated. Also, the question of how the communication skills of the participating nurses can be improved by a communication skills training programme is addressed. A power analysis was calculated in order to determine the population size. This revealed that a sample size of 2 x 30 (30 in the experimental condition and 30 in the control condition) would result in an acceptable power coefficient. In fact, we recruited 53 registered (ward) nurses who were willing to participate.

A major strength of the study was that the participants were rewarded for their participation by receiving a training in communicating skills during the study (experimental group) or afterwards (control group).

\section{Simulated patients}

Simulated patients were used to answer the research question. The advantage of the simulated patient technique is that it directly assesses nurses' communication skills that are important during the daily performance in nursing practice. Further, there was an elaborate and standardized script, allowing nurses to test their skills. This improves comparability between nurses as patient variations may be reduced.

Each nurse completed one video taped admission interview with an actor. In total, three actors participated. The actors were trained professionals who played a recently diagnosed cancer patient who had arrived on the ward for admission. The actors were instructed to play a cancer patient according to the scenario which was developed specifically for this study. In order to write a realistic 
and elaborate scenario including significant elements to test the nurses on their skills, an oncologist, an oncology nurse and a cancer patient checked the script for quality based on their specific expertise.

The script related to a middle-aged female cancer patient who was being admitted for cancer treatment. The treatment was curative. The underlying emotions arising from confrontation with a lifethreatening disease, like resistance, anger, denial and anxiety, were central themes.

For each nurse, the script was standard, but small adaptions were made for each medical specialism. The participating nurses within the different medical specialisms were comparable, as cancer patients experience the same emotions after being diagnosed, regardless of the kind and stage of the disease, and as the admission procedure within the different medical disciplines was the same.

\section{Assessment}

The participating nurses were asked to go through the admission procedure with the simulated patient in the same way as they did on the ward with actual patients. The interviews with the simulated patients lasted no more than 20 minutes After 20 minutes, the procedure was interrupted. The nurses did not have to complete the admission procedure, although they could finish it earlier than the 20 minutes limit. The mean length of the interviews was 18:42 minutes (SD 2:58 minutes).

Directly after the admission interview, each participant had a short encounter with the actor and the researcher, during which the nurse had the opportunity to report their feelings of the experience. Although in general the participants experienced some stress before the admission interview, the majority of them reported afterwards that they forgot that they were interacting with an actor and videotaped, which meant that stress did not really affect their behaviour. On the whole, participants experienced the encounter with the simulated patient as a real life admission interview.

\section{Observation scheme}

Affective and instrumental communication. The 53 videotaped admission conversations with simulated patients were observed using the Roter Interaction Analysis System (RIAS) (Roter 1989). In this system, a distinction is made between instrumental or task-related and affective or socioemotional verbal communication. The RIAS was originally designed to code doctor and patient communication, but has also proved to be reliable with respect to the observation of nurse-patient interactions (Gruijter \& de Schirm 1995, Caris-Verhallen et al. 1999).

In this study, some small adaptions were made, tailored to the nurse-patient interaction in a clinical oncology setting. The adapted version included 32 behavioural categories for the nurses (see Table 2). Each nurse utterance was coded into one of the instrumental or affective categories, which are mutual exclusive. An utterance is a communication unit which conveys one thought, or is related to one specific interest. An utterance can vary from one word to a sentence.

\section{[ TABLE 2 ]}

Patients' utterances can also be coded with the RIAS. These are important because patients can differ widely in their communication style which, consequently, will have an impact on nurses' communicative behaviours. However, this study focuses on nurses' communication behaviours only as the variability in patient behaviour in a standardized setting is controlled. More precisely, patient communication was performed by the actor in the same way for each participant. For this reason, it was not necessary to code the patients' utterances.

Instrumental communication consists of categories which contain all items with respect to nursing and medical topics, items about the organization on the ward and services, and verbal expressions about lifestyle issues and psychosocial topics. Further, instrumental communication consists of categories that indicate guidance and direction through the conversation, such as orientation and instructing, requests for clarification, asking for opinions and asking for understanding (see Table 2).

During the history-taking stage of the admission interview, the use of open questions is important in exploring, alternating with closed questions (among others requests for clarification) in order to gain supplementary information.

During the information-giving stage of the admission interview the use of skills that structure the information, for example giving orientations, is significant. Further it is important to avoid a 
monologue. This can be achieved by using skills that involve the patient during information giving, for example, by asking them about understanding of the information, and by asking for their opinion and experience. Affective communication consists of the categories which refer to those aspects needed to establish trusting relationships between nurses and patients in order to facilitate information exchange. Additionally, affective communication refers to nurses' social conversation that has no particular function in nursing activities, such as personal statements and jokes (see Table 2).

During the admission procedure in particular, affective communication is important in encouraging the patient to disclose concerns. Examples of affective behaviours are paraphrases, showing concern, showing empathy, showing optimism and understanding. These behaviours convey respect, attention and intimacy, and provide companionship and encouragement (Krishnasamy 1996b, Wouda \& van de Wiel 1996, Roter 1989).

Based on the research of Caris-Verhallen et al. (1999), we also observed five affective nonverbal affective nurse behaviours. These also appear to be important in the establishment of the nurse-patient relationship, including patient-directed gaze, affirmative head nodding, smiling, leaning forward and affective touch (Heintzman et al. 1993, Caris-Verhallen et al. 1998). These behaviours convey involvement, closeness, friendliness and attentiveness. They are not necessary in performing nursing tasks, but do facilitate verbal interaction between nurses and patients (see Table 3).

\section{[ TABLE 3 ]}

\section{Reliability of the observations}

The affective and instrumental communication between nurses and cancer patients was observed by two independent raters directly from video recordings using the CAMERA computer system which is especially designed to code the observed behavioural interactions from video recordings (Iec ProGAMMA 1994).

Pearson's product-moment correlation coefficients were used to measure the interobserver reliability, based on 20\% (10 interviews) of the total number of videotaped admission conversations. Two observers rated the same 10 interviews.

Inter-observer correlations for the verbal instrumental behaviours ranged from $0 ; 54$ to $0 ; 94$; for the verbal affective behaviours interobserver correlations ranged from 0!66 to 0:94 (see Table 2).

Inter-observer correlations for the nonverbal affective behaviours ranged from 0!66 to 0-86 (see Table 3). The nonverbal behaviours forward leaning and affective touch were performed too rarely by the nurses to allow measurement of interobserver reliability.

\section{RESULTS}

In order to answer the research question, the ratio of instrumental to affective communication was examined first. The results show that $62 \%$ of the communication behaviours employed by nurses were instrumental and 38\% were affective. This means that the majority of the nurses' utterances concerned instrumental communication (see Table 4).

\section{[ TABLE 4 ]}

Next, the occurrence of nurses' communication behaviours within the affective and instrumental categories were examined.

It appeared that a relatively large part of affective communication was related to the more global affective behaviours, such as giving agreements (19\%) and paraphrases (10\%). The minority of the affective utterances was related to specific affective behaviours such as showing concern (2\%), empathy (2\%) and providing reassurance/optimism (2\%).

Within the instrumental categories, the most communication by the nurses consisted of providing medical information (24\%), followed by information about psychosocial issues (11\%), and about the organization of the ward (6\%). Further, it appeared that few utterances were related to structuring communication behaviours such as giving orientation (3\%) and requests for clarification ( $0 \%)$. 
Additionally, few utterances were related to behaviours that involve the patient during the discourse such as asking about their understanding (1\%), and asking for their opinion (1\%).

With regard to the facilitating verbal skills of nurses, which have been shown to be important in the nursing literature, the ratio of open to closed questions was also investigated. Open questions have a probing intent, and facilitate patients to respond freely about affective or medical topics. Closed questions are direct questions that ask for specific information and consequently limit responses to a yes or no answer. Table 5 shows that the nurses asked predominantly closed questions (88\%).

\section{[TABLE 5]}

Finally, the nurses' nonverbal affective communication with recently diagnosed cancer patients during the admission conversation was investigated.

Table 3 shows that patient-directed gaze occurred most of the time. Affirmative head nodding was also a frequently used nonverbal behaviour. Further it appeared that smiling, forward leaning and affective touch occurred relatively rarely.

\section{DISCUSSION}

In this study, the balance of affective and instrumental communication employed by nurses during the admission interview with newly diagnosed cancer patients was investigated. For this purpose, admission interviews by 53 ward nurses with simulated cancer patients were videotaped and analysed with the RIAS, in which a distinction is made between instrumental and affective communication (Roter 1989).

The results show that nurses predominantly employed instrumental communication, mostly consisting of giving information about medical topics. Structuring behaviour and behaviour that involves the patient in the conversation, which seem to be important instrumental skills during the admission, were rarely used. When looking at the way in which nurses asked questions, it appeared that they mostly used closed questions, which limit the patient's expression of feelings and concerns. Affective communication occurred in about one-third of the interactions, but was more related with global affect ratings such as agreements and paraphrases than to specific affective behaviour such as showing empathy, concern and optimism.

With regard to nurses' nonverbal affective communication, patient-directed gaze occurred most of the time. This can be explained by the fact that nurse and patient were sitting at a table in front of each other. Nursing activities during the admission were mainly characterized by information exchange. Nurses therefore used a great part of the time for eye contact with the patient. Leaning forward and affective touch occurred rarely. Although the simulated patient was acting in a distressed way, nurses scarcely used behaviours which are important in creating a trusting relationship.

These results indicate that an imbalance does indeed exist in nurses' use of instrumental and affective behaviours: nurses predominantly gave information about medical topics, which certainly is an important aspect of the admission procedure. However, they rarely made any assessment of the patient's understanding of the situation. Neither did they explore the patient's feelings actively, and they rarely discussed the emotional aspects of the disease in order to create a comforting and helpful atmosphere. These findings agree with those in the literature which show an imbalance in nurses' use of both types of communication, characterized by an overwhelming medical concern (Webster 1981, Bond 1983, Dennisson 1995) and neglect of the emotional component (Webster 1981, Degner et al. 1991, Heaven \& Maguire 1996). These behaviours are especially viewed by patients as unsupportive (Krishanamy 1996a), which leads to dissatisfaction (Suominen et al. 1995).

Other studies show that cancer patients' need to disclose concerns is met only when nurses are willing to explore and listen to these concerns. Reid Ponte (1992) found that the more the nurses showed empathy, the more concerns were disclosed by patients. Webster (1981) and Degner et al. (1991) found that patients' disclosure of feelings was strongly inhibited by nurses' avoidance behaviours, such as abrupt change of the subject of conversation and behaving as though the patient had not spoken at all.

A posthoc look at patients' ratio of instrumental to affective communication behaviour in this study (not reported in the results), revealed that this was the same as the nurses' ratio. This indicates that, in 
accordance with the literature, patients do not express concerns, when they feel that there is opportunity. In other words, the nurses' agenda predominates, and determines the course of interactions with cancer patients.

Emotional care, in addition to practical and medical care, is a crucial task in the professional role of the nurse. However, research shows that discussing emotional issues with patients is at the same time one of the most difficult tasks for nursing professionals because of the unease that they experience when discussing these issues with cancer patients (Webster 1981, Maguire 1985). Webster (1981), for example, found that nurses caring for severely ill cancer patients were conscious of using distancing tactics. They were afraid apparently of losing control over the situation if they became too close to patients.

In future, nurses should be provided systematically with (continuing) training programmes. During these education programmes, they need to learn how to explore and discuss actively emotions and feelings without losing control of their own emotions. Further, they should learn how to integrate emotional care with information-giving techniques, and with practical and medical care during interactions with cancer patients.

A shift in the desired direction as regards the balance of instrumental and affective behaviours performed by nurses could lead to increased satisfaction and well-being for cancer patients as well as for nurses caring for these patients.

\section{Methodological issues}

Because we were primarily interested in the ratio of affective to instrumental communication by ward nurses during the admission interview with cancer patients, the simulated patient method was used in order to answer our research question. This method has the advantage that variations among patients may be reduced as a consequence of a standardized situation. However, up till now the validity of the simulated patient method has scarcely been investigated in nursing research. In current medical and nursing research in this area a distinction is frequently made between 'competence' as an outcome variable, measured with simulated patients, and 'performance' as an outcome variable, measured with real or actual patients (Francke et al. 1995, Rethans 1991, Pieters 1991, Ram et al. 1999). Competence concerns the level to which a health care provider is capable of performing a skill, and performance to how a health care provider actually performs a skill in day to day practice (Pieters 1991).

An interesting topic of research would be further investigation of the validity of working with the simulated patient method. This could expand insight into the extent to which communication skills of nurses, as measured with simulated patients, can predict communicative behaviours with actual patients in day to day practice. We are currently conducting a validation study in this area.

\section{ACKNOWLEDGEMENT}

This study was funded by the Dutch Cancer Foundation.

\section{REFERENCES}

Bensing J.M. (1991) Doctor-patient communication and the quality of care. An observation study into affective and instrumental 13 behavior in general practice. PhD Dissertation, NIVEL, Utrecht, The Netherlands.

Bond S. (1983) Nurses' communication with cancer patients. In Nursing Research Ten Studies in Patient Care. Development in Nursing Research Vol 2 (Jenifer Wilson-Barnett ed.) pp. 57-77, 14 John Wiley \& Sons, New York.

Caris-Verhallen W.M.C.M., Kerkstra A., van der Heijden P.G.M. \& Bensing J.M. (1998) Nurse-elderly communication in home care and institutional care: an explorative study. International Journal of Nursing Studies 35, 95-108.

Caris-Verhallen W.M.C.M., Kerkstra A. \& Bensing J.M. (1999) Nonverbal behaviour in nurse-elderly patient communication. Journal of Advanced Nursing 29, 808-818.

Chaitchik S., Kreitler S.D., Shaked S., Schwartz I. \& Rosin. R. (1992) Doctor-patient communication in a cancer ward. Journal of Cancer Education 1, 41-54.

Degner L.F., Gow C.M. \& Thompson L.A. (1991) Critical nursing behaviours in care for the dying. Cancer Nursing 14, 246-253.

Dennison S. (1995) An exploration of the communication that takes place between nurses and patients whilst cancer chemotherapy is administered. Journal of Nursing Forum 4, 227-233. 
Kruijver, I.P.M., Kerkstra, A., Bensing, J.M., Wiel, H.B.M. van der

Communication skills of nurses during interactions with simulated cancer patients.

Journal of Advanced Nursing: 34, 2001, nr. 6, p. 772-779

Ersscher S. \& Tutton E. (1991) Primary Nursing in Perspective. 15 Scutari Press, London.

Fallowfield L.J. (1988) Counseling for patients with cancer. British Medical Journal 297, 727-729.

Faulkner A. (1993) Teaching Interactive Skills. Chapman \& Hall, London.

Francke A.L., Garssen B. \& Huijer Abu-Saad H. (1991) Determinants of changes in nurses' behaviour after continuing education: a 17 literature review. Journal of Advanced Nursing 21, 371-377.

Gruijter I. \& de Schirm M. (1995) Communicatie met oudere patienten [Communication with elderly patients]. Master Thesis. University of Utrecht, Utrecht.

Hall J.A., Roter D.L. \& Katz B.A. (1987) Task versus socioemotional behaviors in physicians. Medical Care 25, 399-412.

Harrison J., Maguire P., Ibbotson T., Macleod R. \& Hopwood P. (1994) Concerns, confiding and psychiatric disorders in newly diagnosed cancer patients: a descriptive study. Psycho-Oncology $\mathbf{3}$, 173-179.

Heaven C.M. \& Maguire P. (1996) Training hospice nurses to elicit patient concerns. Journal of Advanced Nursing 23, 280-286.

Heintzman M., Leathers D.G., Parrott R.L. \& Caims IIla B. (1993) Nonverbal rapport-building behaviours' effect on perceptions of a supervisor. Management Communication Quarterly 7, 181208.

Iec ProGAMMA (1994) User Manual CAMERA: a system for collecting and correcting behavioural data. lec ProGAMMA, Groningen, the Netherlands.

Krishnasamy M. (1996a) What do cancer patients identify as supportive and unsupportive behaviour of nurses? A pilot study. European Journal of Cancer Care 5, 103-110.

Krishnasamy M. (1996b) Social support and the patient with cancer: a consideration of the literature. Journal of Advanced Nursing 23, 757-762.

Kruijver I.P.M., Kerkstra A., Bensing J. \& van de Wiel H.J. (2000a) Nurse-patient communication in cancer care. A review of the literature. Cancer Nursing, 23, 20-31.

Kruijver P.P.M., Kerkstra A., Francke A.L., Bensing J.M. \& van de Wiel H.B.M. (2000b) Evaluation of communication training programs in nursing care: a review of the literature. Patient Education and Counselling 39, 129-145.

Maguire P. (1985) Barriers to psychological care of the dying. British 18 Medical Journal 291, 17111713.

Maguire P. (1995) Psychosocial interventions to reduce affective disorders in cancer patients: research priorities. Psycho-Oncology 4, 113-119.

Maguire P. \& Faulkner A. $(1988)$ Improve the counseling skills for 19 doctors and nurses in cancer. British Medical Journal 297, 847-849.

Maguire P., Faulkner A., Booth K., Elliot C. \& Hillier V. (1996) Helping cancer patients disclose their feelings. European Journal of Cancer 32A, 78-81.

Northouse P.G. \& Northouse L.L. (1987) Communication and cancer: issues confronting patients, health professionals, and family members. Journal of Psychosocial Oncology 5, 17-46.

Pieters H.M. \& De Utrechtse Consult Evaluatie Methode (1991) Vaardigheden in consultvoering van huisartsen in opleiding getoetst. (The Utrecht Consultation Assessment Method: The assessment of consultation skills of trainees in the vocational training). 21 Dissertation, University of Utrecht, MEDITekst, Lelystad.

Ram P., Vleuten van der C., Rethans J.J., Grol R. \& Aretz K. (1999) Assessment of practical family physicians: comparison of observation in a multiple-station examination using standardized patients with observation of consultations in daily practice. Academic Medicine 74, 62-74.

Reid Ponte P. (1992) Distress in cancer patients and primary nurses' empathy skills. Cancer Nursing 16, 304-309.

Rethans J.J. (1991) Does competence predict performance? Standardized patients as means to investigate the relationship between competence and performance of general practitioners. $22 \mathrm{PhD}$ Dissertation. Thesis Publishers, Amsterdam.

Roter D.L. (1989) The Roter Method of Interaction Process Analysis. Johns Hopkins University, Baltimore.

Suominen T., Leini-Kilpi H. \& Laippala P. (1995) Who provides support and how? Cancer Nursing 18, 278-285.

Webster M.E. (1981) Communication with dying patients. Nursing Times 4, 999-1002.

Wilkinson S. (1991) Factors which influence how nurses communicate with cancer patients. Journal of Advanced Nursing 16, 677-688.

Wouda J. \& Van de Wiel H.B.M. (1996) Beter zorgen voor, minder zorgen door: psychosociale begeleiding van oncologische patienten. Stichting voor toegepaste medische psychologie, Ahmas, Groningen. 
Kruijver, I.P.M., Kerkstra, A., Bensing, J.M., Wiel, H.B.M. van der

Communication skills of nurses during interactions with simulated cancer patients.

Journal of Advanced Nursing: 34, 2001, nr. 6, p. 772-779

\section{TABLES}

Table 1 Background characteristics of the participating nurses $(n=53)$

\begin{tabular}{lrr}
\hline & $n$ & SD \\
\hline Gender (\%) & 15 & \\
$\quad$ Men & 85 & \\
Women & & \\
Age (years) & 32 & 8 \\
$\quad$ Mean age & & \\
Educational level (\%) & 34 & \\
$\quad$ HBO (Dutch higher educational level) & 62 & \\
MBO (Dutch secondary educational level) & 4 & \\
$\quad$ Missing & 11 & 8 \\
Mean years of employment (years) & 5 & 5 \\
Mean years of employment in oncology (years) & & \\
\hline
\end{tabular}

Table 3 Occurrence of nonverbal behaviours $(n=53)$

\begin{tabular}{|c|c|c|c|c|}
\hline & $\%$ & Mean & SD & $\begin{array}{l}\text { Inter-rater } \\
\text { reliability } \\
\text { (Pearson's r) }\end{array}$ \\
\hline \multicolumn{5}{|l|}{ Minutes } \\
\hline Patient directed gaze & 88 & $16 \cdot 1$ & $2 \cdot 7$ & $0 \cdot 84^{* *}$ \\
\hline \multicolumn{5}{|l|}{ Frequencies } \\
\hline Affirmative head nodding & & $21 \cdot 6$ & $11 \cdot 4$ & $0 \cdot 86^{* *}$ \\
\hline Smiling & & $4 \cdot 1$ & $4 \cdot 7$ & 0.66 \\
\hline Forward leaning & & $1 \cdot 4$ & $2 \cdot 6$ & \\
\hline Affective touch & & $0 \cdot 7$ & $1 \cdot 4$ & \\
\hline
\end{tabular}

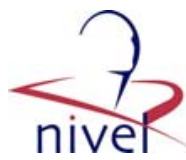

Table 2 Occurrence of nurses' verbal behaviours within the instrumental/affective categories

\begin{tabular}{|c|c|c|c|c|}
\hline & Range & Mean frequency & $\%$ & $\begin{array}{l}\text { Inter-rater reliability } \\
\text { (Pearson's } r \text { ) }\end{array}$ \\
\hline \multicolumn{5}{|l|}{ Affective } \\
\hline Personal remarks/social conversation & $0-23$ & 5 & 3 & $0 \cdot 88^{* *}$ \\
\hline Jokes/laughs & $0-7$ & $0 \cdot 5$ & - & \\
\hline Approval & $0-4$ & $0 \cdot 3$ & - & \\
\hline Compliments & $0-2$ & - & - & \\
\hline Shows concern/worry & $0-10$ & 3 & 2 & $0.65^{*}$ \\
\hline Shows agreement/understanding & $7-110$ & 39 & 19 & $0.94 * *$ \\
\hline Paraphrase/check & $4-46$ & 21 & 10 & $0 \cdot 61$ \\
\hline Empathy/legitimize & $0-19$ & 4 & 2 & $0 \cdot 54$ \\
\hline Reassurance/encouragement/optimism & $0-32$ & 4 & 2 & $0 \cdot 72 *$ \\
\hline Shows partnership & $0-32$ & $0 \cdot 7$ & - & \\
\hline Disapproval & $0-1$ & - & - & \\
\hline Criticism & - & - & - & \\
\hline Asks for reassurances & $0-2$ & - & - & \\
\hline Total utterances & $37-54$ & 77 & 38 & \\
\hline \multicolumn{5}{|l|}{ Instrumental } \\
\hline Orientations/instructions & $1-21$ & 6 & 3 & $0 \cdot 86 * *$ \\
\hline Asks for clarification & $0-4$ & $0 \cdot 3$ & - & \\
\hline Asks for understanding & $0-11$ & 2 & 1 & \\
\hline Asks for opinion & $0-8$ & 1 & 1 & \\
\hline Closed questions: medical/therapeutic items & $0-26$ & 10 & 5 & $0 \cdot 86 * *$ \\
\hline Closed questions: hospital/ward items & $0-5$ & $0 \cdot 7$ & - & \\
\hline Closed questions: lifestyle items & $0-20$ & 7 & 3 & $0 \cdot 94 * *$ \\
\hline Closed questions: psycho-social/feelings & $2-38$ & 9 & 5 & $0 \cdot 71 *$ \\
\hline Open questions: medical/therapeutic items & $0-7$ & 2 & 1 & \\
\hline Open questions: hospital/ward items & $0-1$ & - & - & \\
\hline Open questions: lifestyle items & $0-3$ & $0 \cdot 1$ & - & \\
\hline Open questions: psycho-social items/feelings & $0-11$ & 4 & - & \\
\hline Information related to medical/therapeutic items & $13-110$ & 50 & 24 & $0 \cdot 94 * *$ \\
\hline Information related to hospital/ward items & $0-96$ & 12 & 6 & $0 \cdot 71^{*}$ \\
\hline Information related to lifestyle items & $0-19$ & 1 & - & \\
\hline Information related to psycho-social items/feelings & $2-58$ & 24 & 11 & $0 \cdot 89 * *$ \\
\hline Counsels medical/therapeutic behaviour & $0-8$ & $0 \cdot 7$ & - & \\
\hline Counsels lifestyle behaviour and feelings & $0-19$ & 3 & 1 & \\
\hline Rest & $0-4$ & $0 \cdot 4$ & - & \\
\hline Total utterances & $55-262$ & 131 & 62 & \\
\hline
\end{tabular}

$* P<0.05, * P<0.01$. 
Kruijver, I.P.M., Kerkstra, A., Bensing, J.M., Wiel, H.B.M. van der

Communication skills of nurses during interactions with simulated cancer patients.

Journal of Advanced Nursing: 34, 2001, nr. 6, p. 772-779

Table 4 Occurrence of nurses' verbal behaviours: instrumental vs. affective $(n=53)$

\begin{tabular}{lccc}
\hline & Range & $\begin{array}{l}\text { Mean } \\
\text { frequency }\end{array}$ & $\%$ \\
\hline Affective behaviours & $37-154$ & 77 & 38 \\
Instrumental behaviours & $55-262$ & 131 & 62 \\
Total utterances & $98-338$ & 208 & 100 \\
\hline
\end{tabular}

Table 5 Question asking $(n=53)$

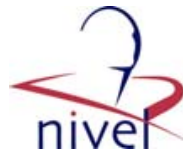

\begin{tabular}{lccc}
\hline & Range & Mean frequency & $\%$ \\
\hline Open questions & $1-16$ & 5 & 18 \\
Closed questions & $8-63$ & 27 & 82 \\
Total questions & $9-64$ & 32 & 100 \\
\hline
\end{tabular}

